\title{
Comparative Study of Chemical Approaches to the Solid-Phase Synthesis of a Tumor-Seeking $\alpha$-MSH Analogue
}

\author{
Magdalena Valldosera - Marta Monsò - Catarina Xavier • \\ Paula Raposinho · João D. G. Correia • Isabel Santos • \\ Paula Gomes
}

Accepted: 30 July 2008/Published online: 21 August 2008

(C) Springer Science+Business Media, LLC 2008

\begin{abstract}
The synthesis of a cyclic melanocortin analogue (H-pz- $\beta$ Ala-Nle-cyclo[Asp-His-DPhe-Arg-Trp-Lys]- $\mathrm{NH}_{2}$ ), where the Boc-protected derivative of a metal-chelating pyrazolyl ligand (pz) was inserted as $\mathrm{N}$-terminal residue, was addressed by several different Fmoc/tBu and Boc/Bzl solid-phase strategies. On-resin cyclization was achieved immediately following incorporation of Asp, by condensation of the Asp side chain carboxyl with the Lys side chain primary amine after selective and simultaneous removal of side chain protecting groups. The success of the synthesis was highly dependent on the chemical strategy employed, with Boc/Bzl chemistry giving the best results. On the light of our findings, Fmoc/tBu strategies are not advantageous for the solid-phase synthesis of this particular type of lactam-bridged peptides. Last, but not least, the target peptide was recently found to have promising tumorseeking properties (J Biol Inorg Chem 13:449-459, 2008).
\end{abstract}

Keywords $\alpha$-MSH $\cdot$ Cyclic peptides - Melanocortin · MTII · On-resin lactamization · Orthogonal · SPPS

\section{Introduction}

Intramolecular cyclization has been demonstrated to improve biological properties of bioactive peptides, in

M. Valldosera · M. Monsò · P. Gomes $(\bowtie)$

Departamento de Química, Faculdade de Ciências (DQFCUP), Centro de Investigação em Química da Universidade do Porto (CIQUP), Universidade do Porto, Rua do Campo Alegre 687, 4169-007 Porto, Portugal e-mail: pgomes@fc.up.pt

C. Xavier · P. Raposinho - J. D. G. Correia · I. Santos Departamento de Química, Instituto Tecnológico Nuclear, Estrada Nacional 10, 2686-953 Sacavem, Portugal many cases allowing improving bioavailability, metabolic stability and/or selectivity for a given receptor (Al-Obeidi et al. 1989; Arnott et al. 2006; Besser et al. 2000a, b; Charpentier et al. 1989; Che and Marshall 2006; Flora et al. 2005; Gilon et al. 1991; Gomes et al. 2001; Keramida et al. 2006; Kaul et al. 2005; Liederer et al. 2006; Nielsen et al. 2005; Norgren et al. 2006; Poteau and Trinquier 2005; Reissmann and Imhof 2004). Classically, cyclic peptides have been prepared exclusively in solution or through on-resin assembly of the linear precursor followed by cyclization in solution, but these procedures are affected by undesired cyclo-oligomerization that occurs even at high dilutions. Hence, the pseudo-dilution effect on solid-phase peptide synthesis (SPPS) has given a prominent role to solid-phase cyclization, i.e., performance of the cyclization step while the peptide is still attached to the resin (Rovero 2000).

We are interested in the development of novel cyclic analogues of $\alpha$-melanocyte-stimulating hormone ( $\alpha$-MSH) that can be radio-labeled with ${ }^{99 \mathrm{~m}} \mathrm{Tc}$ for detection of MC1 receptors over-expressed in melanoma. In view of the excellent results with melanotan II peptide (MTII) (Holder and Haskell-Luevano 2004), we have recently proposed peptide pz- $\beta$ Ala-MTII as a promising candidate for that purpose (Raposinho et al. 2008a). pz- $\beta$ Ala-MTII is a side chain-to-side chain cyclic homodetic peptide whose $\mathrm{N}$ terminal residue $(\mathrm{pz})$ is a bifunctional chelating agent required for capture of ${ }^{99 \mathrm{~m}} \mathrm{Tc}$ and available in our lab as the Boc-protected derivative (Raposinho et al. 2008b). The synthesis of pz- $\beta$ Ala-MTII can be envisaged by an entirely solid-phase methodology where normal attachment of the peptide C-terminal residue to the solid support is followed by assembly of the amino acid linear sequence, after which the Lys and Asp side chain protecting groups are selectively removed and lactamization is promoted. Finally, the 
cyclic peptide could be detached from the solid support according to usual procedures.

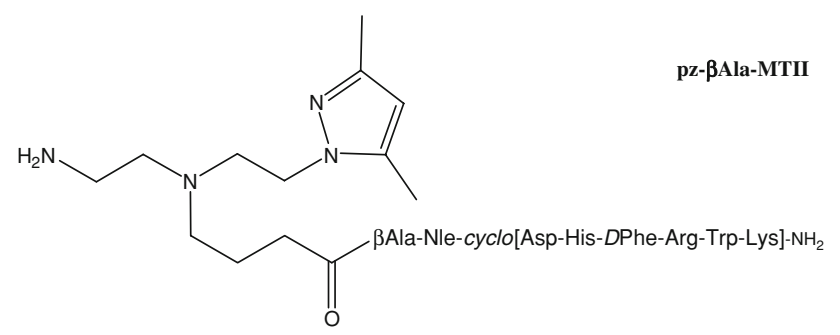

Schiller et al. (1985) have been the first to follow such a strategy, using $\mathrm{N}-\mathrm{Fmoc}$ protected amino acids with Bzl side chain protecting groups, except in the case of the carboxyl and amine functions that were to be cyclized, which were protected with the $\mathrm{tBu}$ and Boc groups, respectively. The final cyclic products were obtained after slow cyclization steps followed by HF cleavage. The same authors have further described the synthesis of more demanding cyclic peptides, based on Boc/Bzl and Fmoc/ Bzl chemistries (Schiller et al. 1988). Another earlier approach for the synthesis of side chain-to-side chain homodetic peptides, described by Felix et al. (1988) was based on the Boc/Bzl chemistry where base-labile Fmoc/ OFm groups (Boc/Bzl/Fm) were used for orthogonal protection of side chains that would be used for intramolecular cyclization. In the 1990s, Hruby and co-workers addressed the synthesis of $\alpha$-MSH analogues like pz1- $\beta$ Ala-MTII following the above approaches (Al-Obeidi et al. 1989; Sugg et al. 1988; Hadley et al. 1997; Hruby et al. 1995). To avoid HF cleavage, Fmoc/tBu strategies based on allyl chemistry (Fmoc/tBu/All) were later proposed by Lyttle and Hudson (1992), and the present diversity of available building blocks for Fmoc/tBu SPPS provides other options, such as the hydrazine-labile ivDde/Dmab (Fmoc/tBu/ Dmab) (Chan et al. 1995; Chhabra et al. 1998) or the hyper-acid labile Mtt/2-PhiPr (Fmoc/tBu/PhiPr) (Aletras et al. 1995; Yue et al. 1993) groups for selective protection of the amine/carboxyl side chains that will form the lactam bridge. We wish to report our comparative study on the application of four different chemical approaches to the synthesis of peptide pz- $\beta$ Ala-MTII, based on diverse orthogonal protection schemes in both Boc/Bzl and Fmoc/ tBu SPPS.

\section{Materials and Methods}

\section{Chemicals}

All amino acids, coupling agents, handles and resins were purchased to NovaBiochem (VWR International-Lisbon,
Portugal). All other chemicals and solvents were from Sigma-Aldrich (Lisbon, Portugal). Boc-pz was prepared inhouse as previously described (Raposinho et al. 2008b).

Instrumentation and Chromatographic Conditions

Mass spectra were acquired either by MALDI-TOF or ESIMS techniques on an Applied Biosystems 4700 Proteomics Analyzer or a LCQ DECA XP ThermoFinnigan spectrometer, respectively. UV-vis analysis was done on a Helios Gamma spectrometer from Thermo Scientific. Reversed-phase high performance liquid chromatography (RP-HPLC) analyses were run on either a Beckman System Gold or a Waters 712, using a Waters Symmetry C-18 column $(5 \mu \mathrm{m} ; 150 \times 3.9 \mathrm{~mm})$ and an elution gradient of $5 \rightarrow 95 \% \mathrm{~B}$ over $30 \mathrm{~min}$, at $1 \mathrm{ml} / \mathrm{min}$ flow, with detection at $220 \mathrm{~nm}$. HPLC solvents were $\mathrm{A}=\mathrm{H}_{2} \mathrm{O}+0.045 \%$ TFA, $\mathrm{B}=\mathrm{MeCN}+0.036 \% \mathrm{TFA}$. Crude mixtures containing the target peptide as main product were purified by RP-HPLC using a semi-preparative Hypersil C-18 column $(10 \mu \mathrm{m}$; $250 \times 8 \mathrm{~mm})$.

Preparation of the Fmoc-Rink-MBHA Resin for Fmoc/ tBu Approaches

Resin MBHA with a functionalization of $0.62 \mathrm{mmol} / \mathrm{g}$ was coupled to the Fmoc-Rink linker (1.5 eq) by employment of $N, N^{\prime}$-diisopropylcarbodiimide (DIPCDI, $1.5 \mathrm{eq}$ ) as coupling agent. Unreacted amino groups were blocked by acetylation with acetic anhydride (20 eq) in the presence of $N$-ethyl- $N, N^{\prime}$-diisopropylamine (DIEA, $20 \mathrm{eq}$ ) and final funcionalization of the Fmoc-Rink-MBHA resin thus obtained was of $0.30 \mathrm{mmol} / \mathrm{g}$, as determined by UV-Vis spectrometry (Gude et al. 2003).

Peptide Synthesis

(a) 1st Approach: The linear sequence of pz- $\beta$ Ala-MTII was assembled in the $\mathrm{C} \rightarrow \mathrm{N}$ direction up until the incorporation of Boc-pz-OH, using TBTU (3 eq) and DIEA (6 eq) to promote amino acid couplings and 20\% piperidine in $N, N$-dimethylformamide (DMF) for Fmoc-removal cycles. FmocAsp(ODmab)OH and FmocLys(ivDde)OH were used for orthogonal removal of their side chain protecting groups prior to the cyclization step (Aletras et al. 1995; Chan et al. 1995). The completion of each coupling step was confirmed by means of the Kaiser test (Kaiser et al. 1970) and, whenever amino acid coupling was not quantitative, a re-coupling step was done using the same molar equivalents as above. Deprotection cycles were also monitored by the Kaiser test and repeated whenever needed. The resin was then treated with $2 \%$ hydrazine in DMF 
(10 min) for simultaneous removal of the Dmab and ivDde side chain protecting groups. Condensation of the Asp and Lys side chains to form the intramolecular lactam bridge was then carried out by using TBTU (6 eq), DIEA (12 eq) and 1-hydroxybenzotriazole (HOBt, 6 eq) for $2 \mathrm{~h}$ (negative Kaiser test). Full deprotection and cleavage of the final peptide from the solid support was performed by treatment of the peptidyl-resin with trifluoroacetic acid containing $2.5 \% \quad \mathrm{H}_{2} \mathrm{O}$ and $2.5 \%$ triisopropylsilane (TFA/ $\mathrm{H}_{2} \mathrm{O} / \mathrm{TIS}$ 95:2.5:2.5). The crude product was analyzed by RP-HPLC and MALDI-TOF MS and found to be a complex mixture that did not contain the target peptide (cf. Table 1).

(b) 2nd Approach: The synthesis was carried out as in (a), but using larger excess of FmocAAOH (6 eq), TBTU (6 eq) and DIEA (12 eq) for the coupling steps and either $50 \%$ piperidine in $N$-methylpirrolidone (NMP) or $20 \%$ piperidine $+5 \%$ 1,8-diazabicyclo-[5.4.0]undec-7-ene (DBU) in DMF for difficult deprotection steps. Once Bocpz-OH was incorporated in the peptidyl-resin, this was repeatedly treated with $2 \%$ hydrazine in DMF until no increase on absorption at $290 \mathrm{~nm}$, due to the indazole byproduct arising from protecting group removal, was detected (cf. Results and Discussion) (Johnson et al. 2000). The resin was then washed with $20 \%$ DIEA in DMF/water 90:10 to overcome eventual problems with sluggish cleavage of the aminobenzyl moiety in the course of Dmab removal (cf. Results and Discussion). Condensation of the Asp and Lys side chains to form the intramolecular lactam bridge was carried out by using PyBOP (4 eq), DIEA (8 eq), and HOBt (4 eq) and allowing the reaction to proceed until a negative Kaiser test was obtained $(\sim 72 \mathrm{~h})$. Full deprotection and cleavage of the final peptide from the solid support was performed as before. The crude product was analyzed by RP-HPLC and MALDI-TOF MS and found to be a complex mixture that only contained traces of the target peptide (cf. Table 1).

(c) 3rd Approach: The synthesis was carried out as described for (b), with the difference that Dmab and ivDde removal and subsequent lactamization were carried out immediately after incorporation of FmocAsp(ODmab) $\mathrm{OH}$, i.e., prior to Fmoc-removal and further assembly of the N-terminal segment pz- $\beta$ Ala-Nle. Simultaneous removal of the Dmab and ivDde protecting groups were carried out by treating the peptidyl-resin with a freshly prepared mixture of hydroxylamine hydrochloride and imidazole in NMP, according to Bradley and co-workers (Díaz-Mochón et al. 2006). The cyclization step was done using PyBOP (8 eq), DIEA (16 eq), and HOBt (8 eq) and allowing the reaction to proceed for $\sim 36 \mathrm{~h}$ (negative Kaiser test). The N-terminal segment was normally assembled thereafter. Full deprotection and cleavage of the final peptide from the solid support was performed as before. The crude product was analyzed by RP-HPLC and MALDI-TOF MS and found to contain the target peptide as the major product (cf. Table 1) that was isolated by semi-preparative RP-HPLC and quantitated by UV-vis. Yield: $27 \%$; calcd $m / z$ for $[\mathrm{M}]^{+} 1302.75$; found: 1303.62 $[\mathrm{M}+\mathrm{H}]^{+}$.

A portion of the peptidyl-resin was cleaved prior to incorporation of the N-terminal pyrazolyl ligand Boc-pz,

Table 1 Summary of MS data on crude products obtained on the synthetic approaches targeted at pz- $\beta$ Ala-MTII ${ }^{\mathrm{a}}$ and based on the ivDde/ ODmab side chain protection scheme

\begin{tabular}{|c|c|c|c|}
\hline Synthetic approach & $m / z$ Observed & Relative abundance $/ \%$ & Compatible peptide fragment \\
\hline \multirow[t]{4}{*}{$1 \mathrm{st}$} & 1190.47 & 7 & pz- $\beta$ Ala-cyclo[AspHisDPheArgTrpLys]- $\mathrm{NH}_{2}$ \\
\hline & 1511.64 & 35 & pz- $\beta$ AlaNleAsp(ODmab)-DPheArgTrpLys- $\mathrm{NH}_{2}$ \\
\hline & 1597.72 & 10 & $-\beta$ AlaNleAspHisDPheArg(Pbf)TrpLys(ivDde)- $\mathrm{NH}_{2}$ \\
\hline & 1641.76 & 100 & $-\beta$ AlaNleAsp(ODmab)His(Trt)DPheArgTrpLys- $\mathrm{NH}_{2}$ \\
\hline \multirow[t]{8}{*}{ 2nd } & 695.73 & 100 & $-\beta$ Ala-His-ArgTrpLys- $\mathrm{NH}_{2}$ \\
\hline & 772.47 & 38 & HisDPheArgTrpLys-NH ${ }_{2}$ \\
\hline & 798.60 & 47 & -Nlecyclo[AspHisDPheArg-Lys]- $\mathrm{NH}_{2}$ \\
\hline & 880.13 & 20 & pz- $\beta$ AlaNleAsp-ArgTrp- $\mathrm{NH}_{2}$ \\
\hline & 982.67 & 15 & -Nlecyclo[AspHisDPheArgTrpLys]- $\mathrm{NH}_{2}$ \\
\hline & 1303.80 & 10 & pz- $\beta$ Ala-MTII \\
\hline & 1388.80 & 30 & pz- $\beta$ AlaNleAspHisDPheArgTrpLys $\left({ }^{\varepsilon} \beta\right.$ Ala $)-\mathrm{NH}_{2}$ \\
\hline & 1597.67 & 35 & $\beta$ AlaNleAspHisDPheArg(Pbf)TrpLys(ivDde)- $\mathrm{NH}_{2}$ \\
\hline \multirow[t]{4}{*}{ 3rd } & 1303.62 & 100 & pz- $\beta$ Ala-MTII \\
\hline & 1466.73 & 44 & pz- $\beta$ AlaNleAsp(ODmab)HisDPheArg-Lys- $\mathrm{NH}_{2}$ \\
\hline & 1580.36 & 25 & pz-NleAsp(ODmab)HisPheArgTrpLys- $\mathrm{NH}_{2}$ \\
\hline & 1744.67 & 15 & pz- $\beta$ Ala-Asp(ODmab)HisDPheArgTrpLys(ivDde)- $\mathrm{NH}_{2}$ \\
\hline
\end{tabular}

${ }^{a}$ pz- $\beta$ Ala-MTII: pz- $\beta$ AlaNlecyclo[AspHisDPheArgTrpLys]; calcd. $m / z=1303.75\left([\mathrm{M}+\mathrm{H}]^{+}\right)$ 
showing that this final step did not much affect the quality of the final product. Therefore, given the laborious procedure behind the production of Boc-pz, all subsequent synthetic approaches (4th to the 6th), tested for comparison, excluded coupling of Boc-pz and thus were terminated after incorporation of $\beta$ Ala.

(d) 4th Approach: The synthesis was carried out as described in (c), but using FmocAsp(O-2-PhiPr)OH and FmocLys(Mtt)OH, instead of the previously referred Asp and Lys derivatives, and cleaving for analysis prior to incorporation of Boc-pz. Simultaneous cleavage of the Asp and Lys side chain protecting groups was carried out after FmocAsp(O-2-PhiPr)OH incorporation, by treatment with $1 \%$ TFA in dichloromethane (DCM) containing 5\% TIS $(3 \times 2 \mathrm{~min})$. Also, FmocHis(Boc)OH was used instead of FmocHis(Trt)OH, to prevent any premature leaching of Trt ?tul?> groups in the course of 2-PhiPr and Mtt removal. Cyclization, done as in (c), did not reach completion after $72 \mathrm{~h}$ and was repeated using 1-ethyl-3-(3-dimethylaminopropyl)carbodiimide hydrochloride (EDC, 4 eq), $\mathrm{N}$ hydroxysuccinimide (HOSu, 4 eq) and DIEA (4 eq) until negative Kaiser test $(\sim 6 \mathrm{~h})$. After full deprotection and cleavage of the final peptide, the crude product was analyzed by RP-HPLC and MALDI-TOF MS and found to be a mixture containing the target peptide as a secondary product.

(e) 5th Approach: The synthesis was carried out as described in (c), but using FmocAsp(O-All)OH and FmocLys(Alloc)OH instead of the previously referred Asp and Lys derivatives. Simultaneous cleavage of the Asp and Lys side chain protecting groups was carried out as described for similar peptides (Grieco et al. 2006), i.e., the allyl and alloc protecting groups were removed with a catalytic amount of $\mathrm{Pd}\left(\mathrm{PPh}_{3}\right)_{4}$ in the presence of triethylsilane (TES) and under inert atmosphere (argon). TES was used to protect Trp and Arg residues from alkylation by cations produced on the cleavage step. Lactamization was then promoted as previously described in (c). After full assembly of the peptide and its cleavage from the resin, the crude product was analyzed by RP-HPLC and MALDI-TOF MS and found to be a complex mixture containing the target peptide as a minor product.

(f) 6th Approach: The synthesis was carried out also by Boc/Bzl chemistry, on a MBHA resin with a functionalization of $0.62 \mathrm{mmol} / \mathrm{g}$. Boc-Asp(O-Fm)OH and BocLys(Fmoc)OH were used and their side chain protecting groups removed immediately after incorporation of Asp by the usual treatment with $20 \%$ piperidine in DMF. Cyclization was subsequently carried out as already described and final cleavage of the fully deprotected peptide from the resin was done by acidolysis with liquid anhydrous HF. The crude product was mainly composed by the target peptide, as concluded from RP-HPLC and MALDI-TOF MS analysis.

\section{Results and Discussion}

As described in Materials and Methods, and depicted on Scheme 1, six SPPS approaches were tested aiming at synthesizing the cyclic lactam peptide pz- $\beta$ Ala-MTII. Three of them were based on the Fmoc/tBu/Dmab chemistry, i.e., used FmocLys(ivDde)OH and FmocAsp(ODmab)OH as selectively protected derivatives for orthogonal removal of their side chain protecting groups prior to the cyclization step and differed in the experimental procedures regarding coupling and deprotection conditions (a) and (b) or concerning the moment at which the cyclization step was carried out in the course of the solid-phase synthesis (c). As shown in Table 1, MS analysis of the crude products showed that the target peptide was only obtained as major product in the last case, i.e., when selective deprotection of the Lys and Asp side chain protecting groups and subsequent lactamization were carried out immediately after FmocAsp (ODmab)OH incorporation, i.e., before assembly of the N-terminal pz- $\beta$ Ala-Nle segment.

A brief analysis of Table 1 can illustrate the path followed until peptide pz- $\beta$ Ala-MTII was successfully synthesized. The first approach led to acyclic peptides still bearing the Dmab side chain protecting group as major products. This encouraged us to try a second approach where not only the coupling and Fmoc-removal conditions were stronger to avoid deletions observed in the previous approach, but also, and more relevantly, the Dmab/ivDde removal cycle with hydrazine was carried out with additional precautions to ensure complete removal of the Dmab group. This group is removed in a two-step reaction where hydrazine firstly cleaves the ivDde moiety, which is released as an indazole by-product that can be detected at $290 \mathrm{~nm}$, after which the p-amino benzyl ester suffers spontaneous cleavage to give the free carboxyl group (Scheme 2) (Chan et al. 1995; Chhabra et al. 1998; Johnson et al. 2000).

Sluggish removal of Dmab has been reported in some cases and washing the peptidyl-resin with $20 \%$ DIEA in DMF/water 90:10 has been suggested as a means to obviate this problem (Johnson et al. 2000). Thus we have carried out several cycles of hydrazine treatment, while monitoring the absorbance of the liquid phase eluted after each cycle, and only carried forward when indazole release was no longer detected. These procedures did not lead to success, as the target peptide was only observed as a minor product in a highly complex crude mixture where main products arose from multiple deletions. The obtention of truncated sequences as major products in such a short sequence is possibly due to bulky side chain protecting groups that interfere with the efficiency of both coupling and deprotection steps. Also, Fmoc-removal conditions may have been too harsh in some instances, as the observation of a 


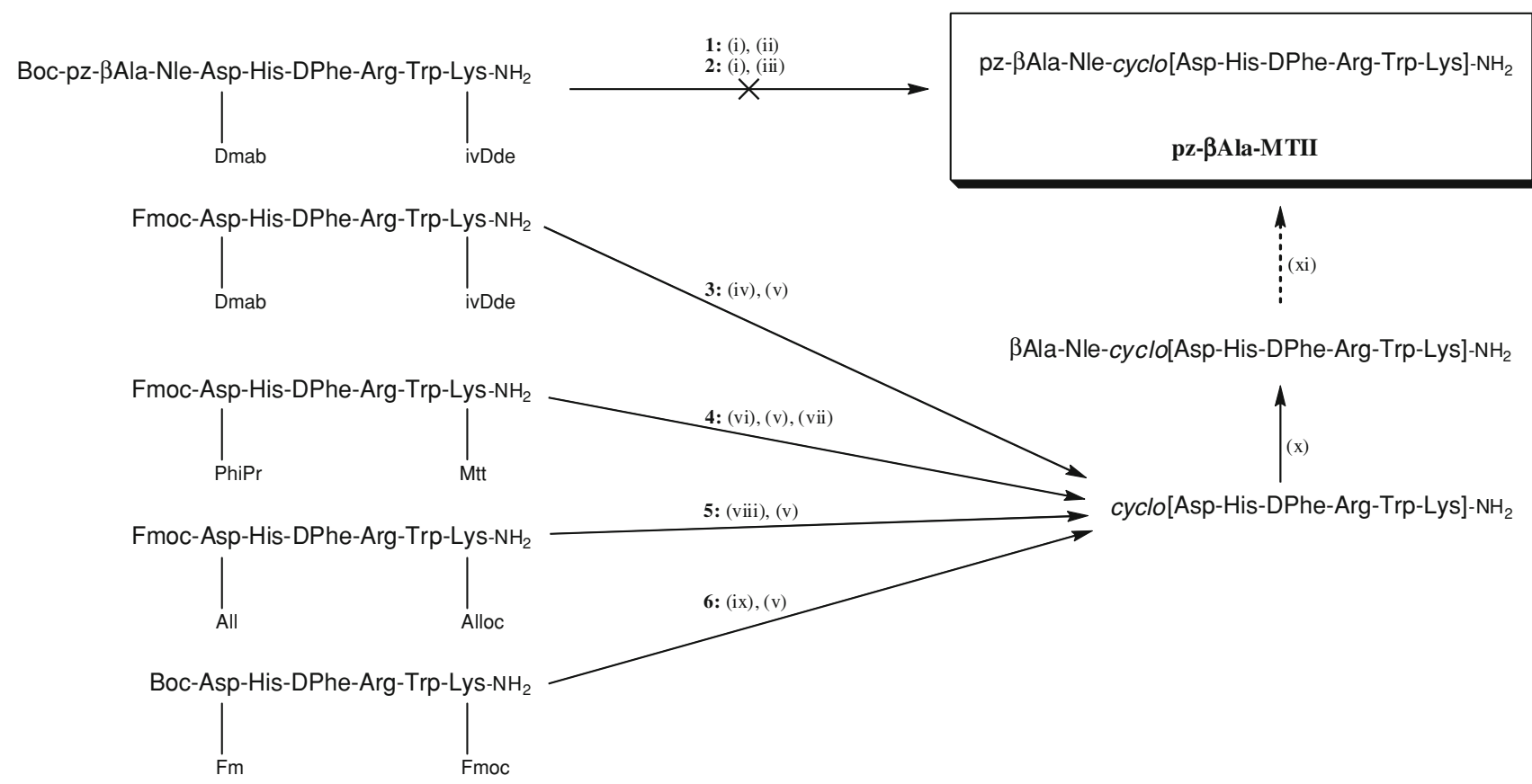

Scheme 1 Synthetic strategies towards the target peptide pz- $\beta$ AlaMTII. 1 and 2, Fmoc/tBu/Dmab with cyclization step after incorporation of Boc-pz: (i) $2 \%$ hydrazine in DMF, (ii) TBTU/DIEA/HOBt 6:12:6 eq., (iii) PyBOP/DIEA/HOBt 4:8:4 eq.; 3, Fmoc/tBu/Dmab with cyclization step after incorporation of Fmoc-Asp(ODmab)-OH: (iv), $\mathrm{NH}_{2} \mathrm{OH} . \mathrm{HCl} / \mathrm{imidazole}$ in $\mathrm{NMP} / \mathrm{CH}_{2} \mathrm{Cl}_{2}$; (v) PyBOP/DIEA/
HOBt 8:16:8 eq.; 4, Fmoc/tBu/PhiPr approach: (vi) 1\% TFA/DCM; (vii) additional lactamization step using EDC/HOSu/DIEA 4:4:4 eq.; 5, Fmoc/tBu/All approach: (viii) $\mathrm{Pd}\left(\mathrm{PhPh}_{3}\right)_{4}$, TES, inert atmosphere; 6, Boc/Bzl/Fm approach: (ix) $20 \%$ piperidine/DMF; (x) normal assembly of the remaining amino acids; (xi) final incorporation of the Boc-pz ligand (not done in all cases)

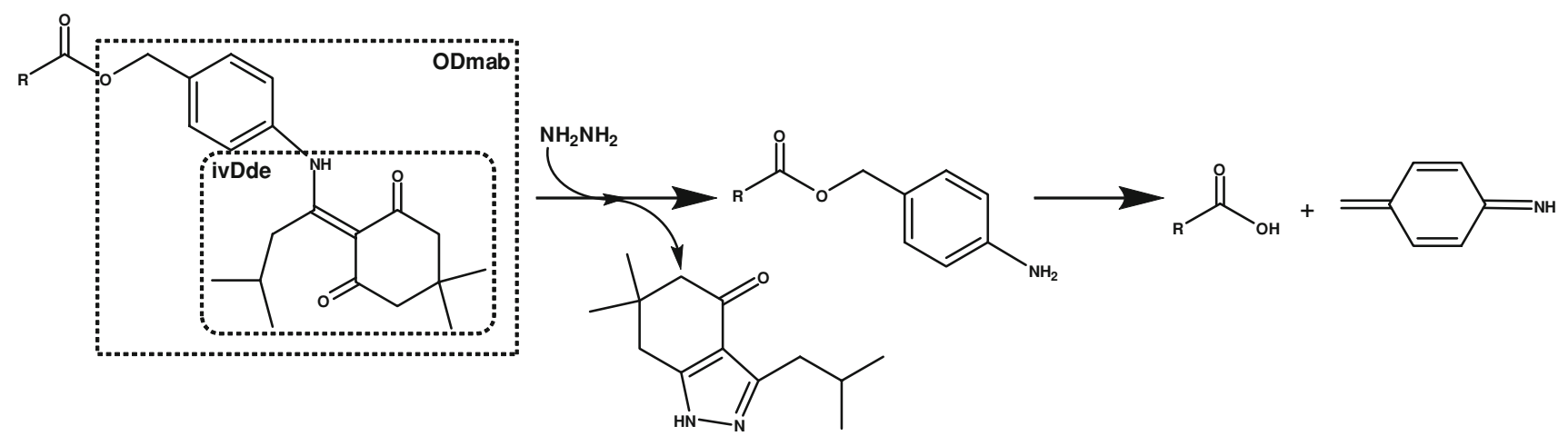

Scheme 2 Removal of Dmab with concomitant release of the ivDde-derived indazole by-product, detectable at $290 \mathrm{~nm}$; adapted from (Johnson et al. 2000)

species at $\mathrm{m} / \mathrm{z} 1388.80$ (Table 1 ) is compatible with the uncyclized sequence having over-incorporation of a $\beta$-Ala; this was most probably due to the fact that ivDde, though more stable to Fmoc-removal conditions than Dde (Chhabra et al. 1998), is not $100 \%$ orthogonal with harsher Fmoc deprotection cycles (extended times, increased piperidine and/or DBU concentrations, etc.). It is worth mentioning that aspartimide formation was not evident, despite the use of Dmab has been claimed to increase the occurrence of such problem (Johnson et al. 2000).
In view of the above results, cyclization at an earlier stage, i.e., immediately after incorporation of FmocAsp(ODmab)OH, seemed advantageous, as ivDde would be exposed to fewer Fmoc-deprotection cycles and the bulky Dmab and ivDde groups would be removed sooner, possibly allowing for a more efficient assembly of the peptide's N-terminal stretch. This strategy, however, is not compatible with the use of hydrazine for Dmab/ivDde removal, as Fmoc is not stable to hydrazine and would be simultaneously cleaved. Nonetheless, Bradley and 
Fig. 1 Crude products from the two best approaches to the synthesis of $\beta$ Ala-MTII, as analyzed by RP-HPLC (retention time of the target peptide $=8.58 \mathrm{~min})-(\mathbf{a})$ Fmoc/ tBu/PhiPr approach; (b) Bocl Bzl/Fm approach; and by MALDI-TOF MS-(c) Fmoc/ tBu/PhiPr approach; (d) Boc/ $\mathrm{Bzl} / \mathrm{Fm}$ approach
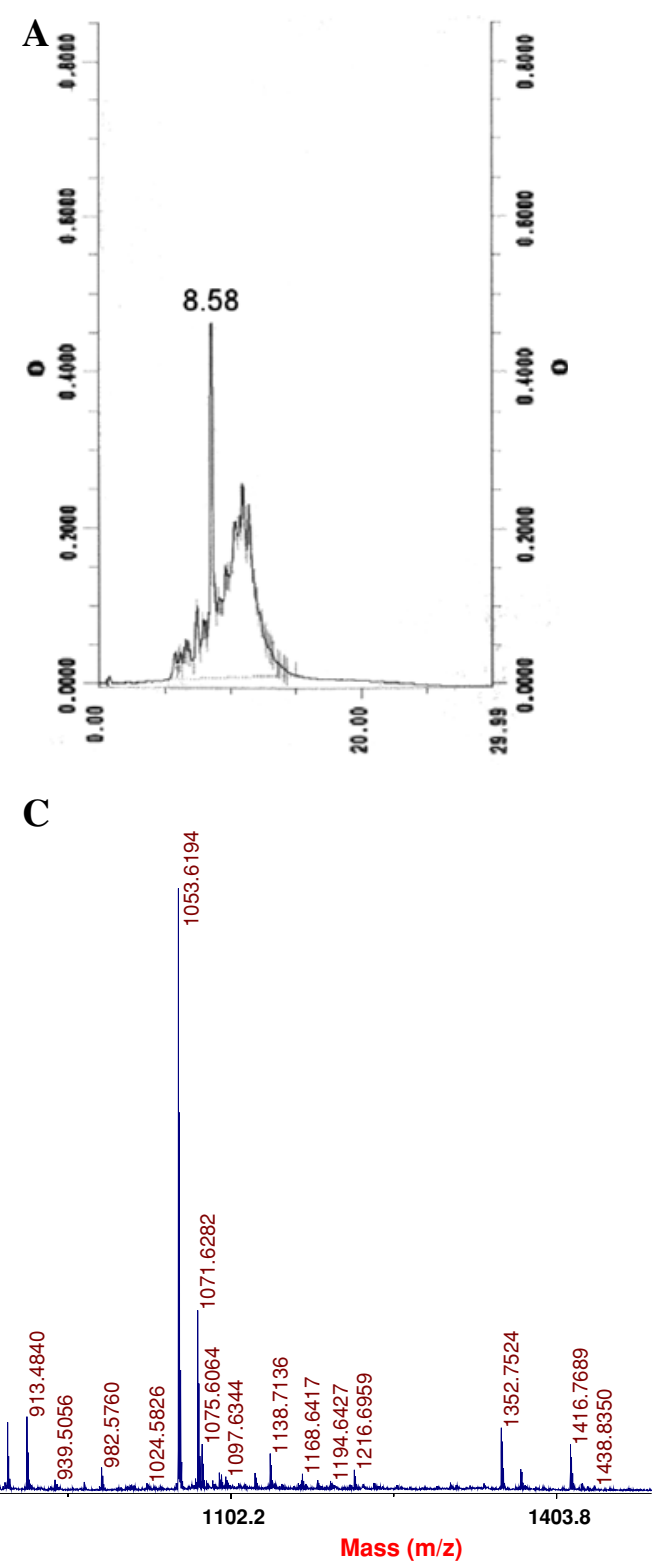
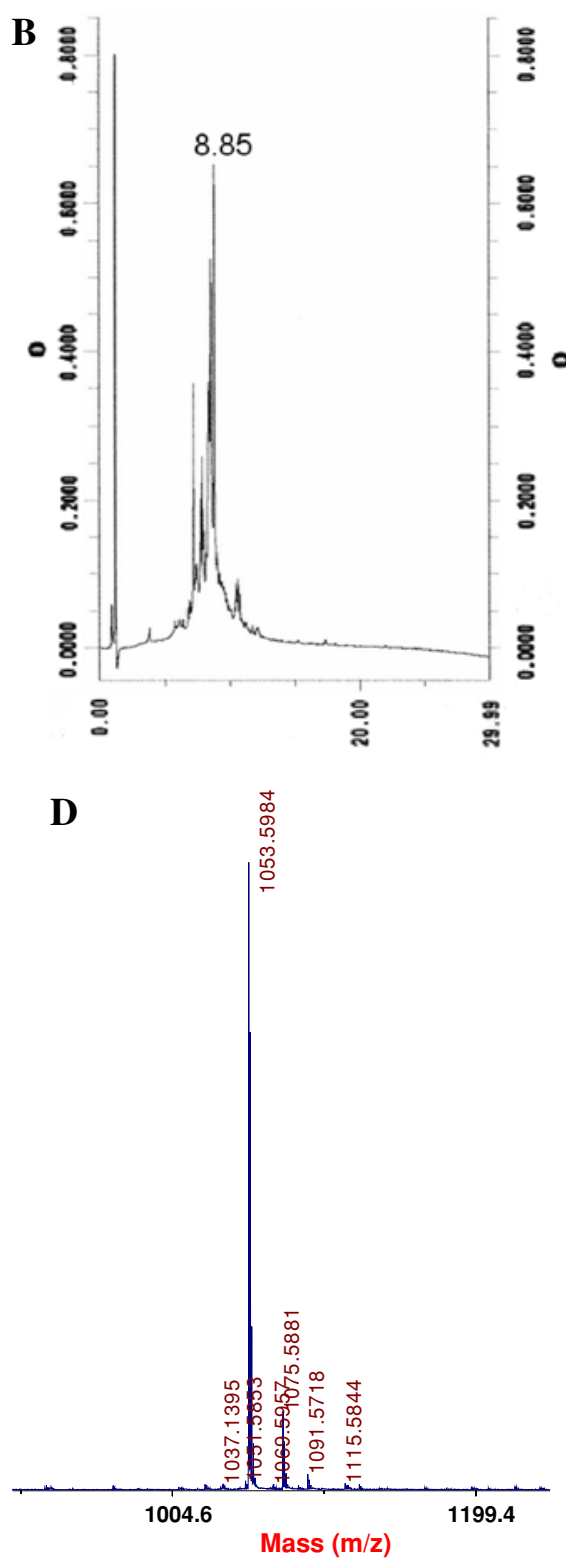

co-workers have recently described a different cleaving cocktail, based on hydroxylamine hydrochloride and imidazole, for selective removal of Dde in the presence of the Fmoc-protecting group (Díaz-Mochón et al. 2006). Hence, it was expectable that both ivDde and Dmab would be selectively cleaved under similar conditions, which was tested in our 3rd synthetic approach. Indeed, as mentioned before, this approach led to the target peptide as one of the main products, even though the crude mixture still possessed three other relevant products, all of them having the Dmab group unremoved (Table 1). Consequently, we decided to further investigate whether alternative methodologies would lead to better results. At this stage, we thought that a comparative study of methodologies to prepare the peptide precursor not incorporating the $\mathrm{N}$-terminal pz moiety
( $\beta$ Ala-MTII) would be preferable, as preparation of Boc-pz is quite laborious. Thus, the synthesis of $\beta$ Ala-MTII was comparatively studied by four different solid-phase methodologies, as described in sub-sections (c) to (f), three of them by Fmoc/tBu chemistry based on different Asp and Lys side chain protection schemes (ivDde/ODmab, Mtt/ OPhiPr, and Alloc/OAll) and one by Boc/Bzl/Fm chemistry. This allowed us to conclude that the best synthetic approach to peptide $\beta$ Ala-MTII was that based on $\mathrm{Boc} / \mathrm{Bzl} / \mathrm{Fm}$ chemistry, as the crude product obtained was of higher quality (Fig. 1a, c), being immediately followed by the one obtained through application of the Fmoc/tBu/PhiPr strategy (Fig. 1b, d). The classical Fmoc/tBu/All protection scheme led to crude mixtures of lower quality, with the target peptide accompanied by substantial amounts of other 


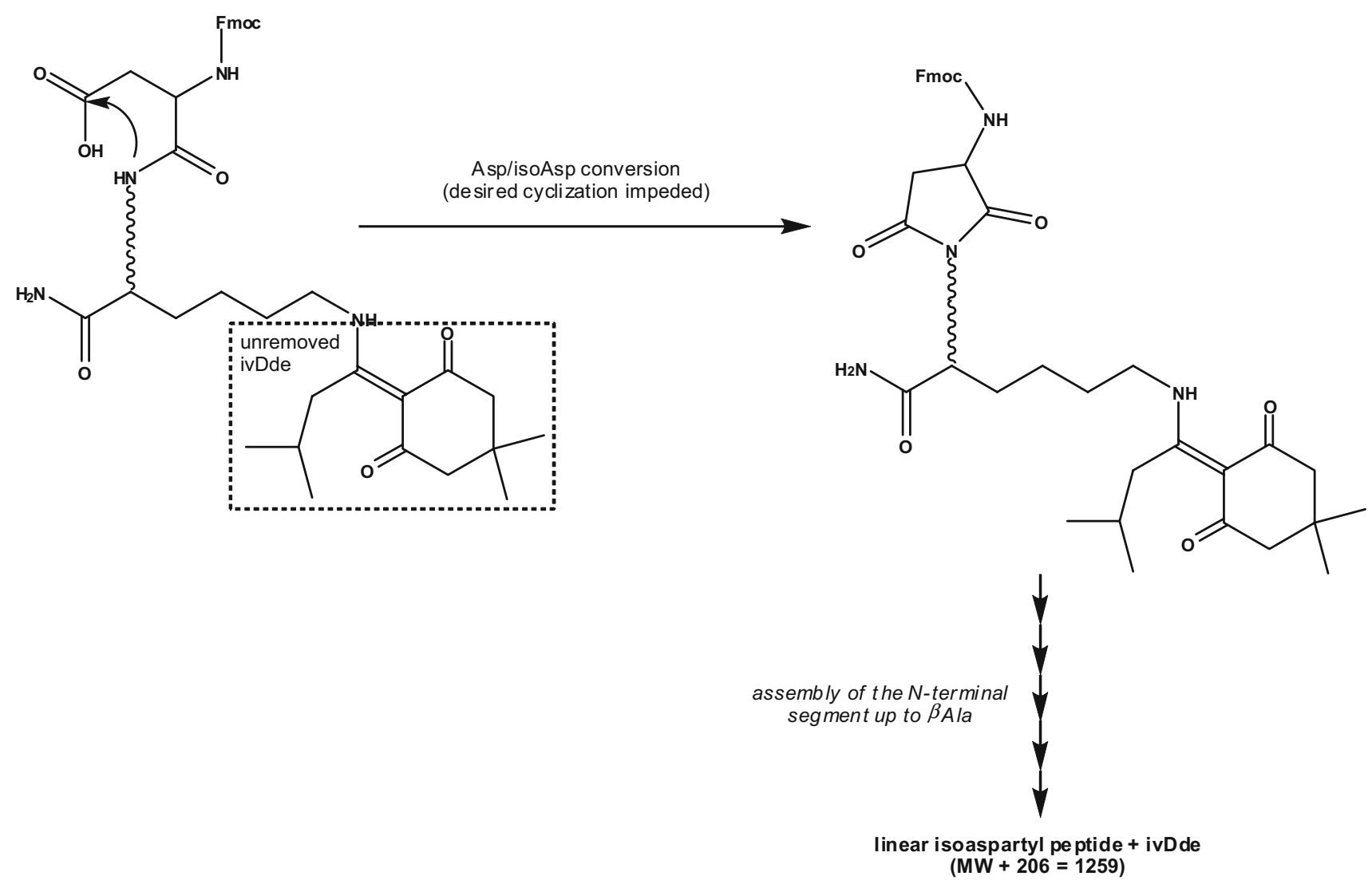

Scheme 3 Proposed side-reaction behind the appearance, on some Fmoc/tBu/Dmab-based syntheses, of a major product with $m / z$, 1259 (see text)

by-products, whereas the Fmoc/tBu/Dmab strategy was the worst of all.

Finally, it is worth mentioning that several additional experiments were conducted where either resin or cyclization conditions were varied, but never led to better results. For instance, the use of the PEG-based resin ChemMatrix (García-Martín et al. 2006) instead of MBHA did not provide any improvement in the Fmoc/tBu strategies used (data not shown), whereas the use of current coupling conditions (usual carbodiimides, TBTU/DIEA) instead of one-step PyBOP/DIEA or two-step PyBOP/DIEA + EDC/HOSu/ DIEA approaches to on-resin lactamization usually led to too sluggish reactions. Also interesting was the consistent observation, in several of the Fmoc/tBu/Dmab-based syntheses assayed, of a major product at $m / z$ 1259. This species could not be easily identified as an "expectable" by-product, being attributed to a combination of non-removal of ivDde with Asp/isoAsp conversion during the "cyclization" step, as proposed in Scheme 3.

\section{Concluding Remarks}

As far as we know, and concerning the solid-phase synthesis of $\alpha-\mathrm{MSH}$ cyclic analogues inspired in melanotan-II
(Dorr et al. 1996), this is the first work where Fmoc/tBu strategies with orthogonal protection schemes other than those based on allyl chemistry were used. As previously mentioned, the pioneer works by Hruby and co-workers were based in Boc/Bzl strategies (Al-Obeidi et al. 1989; Sugg et al. 1988; Hadley et al. 1997; Hruby et al. 1995) that were later employed by other researchers (Bednarek et al. 2001). In the late 1990s, Schaaper et al. (1998) reported the synthesis of cyclic $\alpha$-MSH analogues using Fmoc chemistry, but nothing is described in this paper about the protection schemes used, as their work was mainly focused on the efficiency of the cyclization step. Very recently, Hruby and co-workers have also addressed the synthesis of cyclic $\gamma$-MSH analogues using Fmoc chemistry, but in this case a head-to-side chain lactam bridge was built between an N-terminal Nle and a C-terminal Glu after selective deprotection of its Glu(OAllyl) precursor (Mayorov et al. 2006).

Overall, our findings point to the fact that Boc/Bzl/Fm chemistry is still the best synthetic approach to MTII analogues, ever since its first application to such peptides by Hruby's group. It is true that the panoply of selectivelyprotected Lys and Asp derivatives commercially available for Fmoc/tBu-based approaches to on-resin lactamization widens the universe of alternative tools towards the 
synthesis of homodetic cyclic peptides. However, in our particular case, only the Fmoc/tBu/PhiPr could almost reach the efficiency of the Boc/Bzl/Fm synthesis, having the additional disadvantage of not being economically attractive.

Acknowledgments The authors thank Fundação para a Ciência e Tecnologia (FCT, Portugal) for financial support to the CIQUP research unit. The authors are also indebted to Dr. Alberto Adeva (Barcelona Science Park, Spain).

\section{References}

Aletras A, Barlos K, Gatos D, Koutsogianni S, Mamos P (1995) Preparation of the very acid-sensitive Fmoc-Lys(Mtt)-OH. Int J Peptide Protein Res 45:488-496

Al-Obeidi F, Castrucci AML, Hadley ME, Hruby VJ (1989) Potent and prolonged acting cyclic lactam analogues of $\alpha$-melanotropin: design based on molecular dynamics. J Med Chem 32:25552561

Arnott G, Clayden J, Hamilton SD (2006) Azabicyclic amino acids by stereoselective dearomatizing cyclization of the enolates of $\mathrm{N}$ nicotinoyl glycine derivatives. Org Lett 8:5325-5328

Bednarek MA, MacNeil T, Kalyani RN, Tang R, Van der Ploeg LHT, Weinberg DH (2001) Selective, high affinity peptide antagonists of $\alpha$-melanotropin action at human melanocortin receptor 4: their synthesis and biological evaluation in vitro. J Med Chem 44:3665-3672

Besser D, Müller B, Agricola I, Reissmann S (2000a) Synthesis of differentially protected $\mathrm{N}$-acylated reduced pseudodipeptides as building units for backbone cyclic peptides. J Peptide Sci 6:130138

Besser D, Müller B, Kleinwächter P, Greiner G, Seyfarth L, Steinmetzer T, Arad O, Reissmann S (2000b) Synthesis and characterization of octapeptide somatostatin analogues with backbone cyclization: comparison of different strategies, biological activities and enzymatic stabilities. J Prakt Chem 342:537-545

Chan WC, Bycroft BW, Evans DJ, White PD (1995) A novel 4aminobenzyl ester-based carboxy-protecting group for synthesis of atypical peptides by Fmoc-But solid-phase chemistry. J Chem Soc Chem Comm 1995:2209-2210

Charpentier B, Dor A, Roy P, England P, Pham H, Durieux C, Roques BP (1989) Synthesis and binding affinities of cyclic and related linear analogues of CCK8 selective for central receptors. J Med Chem 32:1184-1190

Che Y, Marshall GR (2006) Engineering cyclic tetrapeptides containing chimeric amino acids as preferred reverse-turn scaffolds. J Med Chem 49:111-124

Chhabra SR, Hothi B, Evans DJ, White PD, Bycroft BW, Chan WC (1998) An appraisal of new variants of Dde amine protecting group for solid phase peptide synthesis. Tetrahedron Lett 39: $1603-1606$

Díaz-Mochón J, Bialy L, Bradley M (2006) Full orthogonality between Dde, Fmoc: the direct synthesis of PNA-peptide conjugates. Org Lett 6:1127-1129

Dorr RT, Lines R, Levine N, Brooks C, Xiang L, Hruby VJ, Hadley ME (1996) Evaluation of melanotan-II, a superpotent cyclic melanotropic peptide in a pilot phase-I clinical study. Life Sci 58:1777-1784

Felix AM, Wang CT, Heimer EP, Fournier A (1988) Applications of BOP reagent in solid phase synthesis. Int J Peptide Protein Res 31:231-238
Flora D, Mo H, Mayer JP, Khan MA, Yan LZ (2005) Detection and control of aspartimide formation in the synthesis of cyclic peptides. Bioorg Med Chem Lett 15:1065-1068

García-Martín F, Quintanar-Audelo M, García-Ramos Y, Cruz LC, Gravel C, Furic R, Côté S, Tulla-Puche J, Albericio F (2006) ChemMatrix, a poly(ethylene glycol)-based support for the solid-phase synthesis of complex peptides. J Comb Chem 8: 213-220

Gilon C, Halle D, Chorev M, Selinger Z, Byk G (1991) Backbone cyclization: a new conformational constraint on peptides. Biopolymers 31:745-750

Gomes P, Giralt E, Andreu D (2001) Antigenicity modulation upon peptide cyclization: application of the GH loop of foot-andmouth disease virus strain C1-Barcelona. Vaccine 19:3459-3466

Grieco P, Cai M, Mayorov AV, Trivedi D, Hruby VJ (2006) Structure-activity studies of new melanocortin peptides containing an aromatic amino acid at the $\mathrm{N}$-terminal position. Peptides 27:472-481

Gude M, Ryf J, White PD (2003) An accurate method for the quantitation of Fmoc-derivatized solid phase supports. Lett Peptide Sci 9:203-206

Hadley ME, Hruby VJ, Sharma SD (1997) Cyclic bridged analogs of $\alpha-\mathrm{MSH}$ and methods thereof. United States Patent 5,683,981. November 4

Holder JR, Haskell-Luevano C (2004) Melanocortin ligands: 30 years of structure-activity relationship (SAR) studies. Med Res Rev 24:325-356

Hruby VJ, Lu D, Sharma SD, Castrucci AL, Kesterson RA, Al-Obeidi FA, Hadley ME, Cone RD (1995) Cyclic lactam $\alpha$-melanotropin analogues of Ac-Nle4-cyclo\{Asp5, DPhe7, Lys10 $\}-\alpha$-melanocyte-stimulating hormone-(4-10)-NH2 with bulky aromatic amino acids at position 7 show high antagonist potency and selectivity at specific melanocortin receptors. J Med Chem 38:3454-3561

Johnson T, Liley M, Cheeseright TJ, Begum F (2000) Problems in the synthesis of cyclic peptides through use of the Dmab protecting group (2000). J Chem Soc, Perkin Trans 1:2811-2820

Kaiser E, Colescott RL, Bossinger CD, Cook PI (1970) Color test for detection of free terminal amino groups in solid-phase synthesis of peptides. Anal Biochem 34:595-598

Kaul R, Surprenant S, Lubell WD (2005) Systematic study of the synthesis of macrocyclic dipeptide $\beta$-turn mimics possessing 8-, 9-, and 10-membered rings by ring-closing metathesis. J Org Chem 70:3838-3844

Keramida M, Tselios T, Mantzourani E, Papazisis K, Mavromoustakos T, Klaussen C, Agelis G, Deraos S, Friligou I, Habibi H, Matsoukas J (2006) Design, synthesis, and molecular modeling of a novel amide-linked cyclic GnRH analogue cyclo(4-9)[Lys4, D-Trp6, Glu9]GnRH: stimulation of gonadotropin gene expression. J Med Chem 49:105-110

Liederer BM, Fuchs T, Velde DV, Siahaan TJ, Borchardt RT (2006) Effects of amino acid chirality and the chemical linker on the cell permeation characteristics of cyclic prodrugs of opioid peptides. J Med Chem 49:1261-1270

Lyttle MH, Hudson D (1992) Allyl based side-chain protection for SPPS. In: Smith JA, Rivier JE (eds) Peptides: chemistry, structure and biology. ESCOM, Leiden, pp 583-584

Mayorov AV, Cai M, Chandler KB, Petrov RR, Van Scoy AR, Yu Z, Tanaka DK, Trivedi D, Hruby VJ (2006) Development of cyclic $\gamma$-MSH analogues with selective hMC3R agonist and hMC3R/ hMC5R antagonist activities. J Med Chem 49:1946-1952

Nielsen TE, Quement SL, Meldal M (2005) Solid-phase synthesis of bicyclic dipeptide mimetics by intramolecular cyclization of alcohols, thiols, amines, and amides with $\mathrm{N}$-acyliminium intermediates. Org Lett 7:3601-3604 
Norgren AS, Büttner F, Prabpai S, Kongsaeree P, Arvidsson PI (2006) 2 -aminoacids in the design of conformationally homogeneous cyclo-peptide scaffolds. J Org Chem 71:6814-6821

Poteau R, Trinquier G (2005) All-cis cyclic peptides. J Am Chem Soc 127:13875-13889

Raposinho PD, Xavier C, Correia JDG, Falcão S, Gomes P, Santos I (2008a) Melanoma targeting with $\alpha$-melanocyte stimulating hormone analogs labeled with fac- $\left[{ }^{99 \mathrm{~m}} \mathrm{Tc}(\mathrm{CO})_{3}\right]^{+}$: effect of cyclization on tumor-seeking properties. J Biol Inorg Chem 13:449-459

Raposinho PD, Correia JDG, Alves S, Botelho MF, Santos AC, Santos I (2008b) A ${ }^{99 \mathrm{~m}} \mathrm{Tc}(\mathrm{CO})_{3}$-labeled pyrazolyl- $\alpha$-melanocyte stimulating hormone analog conjugate for melanoma targeting. Nucl Med Biol 35:91-99

Reissmann S, Imhof D (2004) Development of conformationally restricted analogues of bradykinin and somatostatin using constrained amino acids and different types of cyclization. Curr Med Chem 11:2823-2844
Rovero P (2000) Homodetic cyclic peptides. In: Kates SA, Albericio F (eds) Solid-phase synthesis. Marcel Dekker, Inc., New York, pp 331-364

Schaaper WMM, Adan RAH, Posthum TA, Oosterom J, Gispen W-H, Meloen RH (1998) Synthesis of cyclic $\alpha$-MSH peptides. Lett Peptide Sci 5:205-208

Schiller PW, Nguyen TMD, Miller J (1985) Synthesis of side-chain to side-chain cyclized peptide analogs on solid supports. Int $\mathrm{J}$ Peptide Protein Res 25:171-177

Schiller PW, Nguyen TMD, Lemiueux C (1988) Synthesis and opioid activity profiles of cyclic dynorphin analogs. Tetrahedron 44:733-743

Sugg EE, Castrucci AML, Hadley ME, VanBinst G, Hruby VJ (1988) Cyclic lactam analogs of Ac-[Nle $]-\alpha-\mathrm{MSH}(4-11)-\mathrm{NH}_{2}$. Biochemistry 27:8181-8188

Yue C, Thierry J, Potier P (1993) 2-Phenyl isopropyl esters as carboxyl terminus protecting groups in the fast synthesis of peptide fragments. Tetrahedron Lett 34:323-326 